\title{
ANTIFERTILITY SUBSTANCES AND THEIR ASSESSMENT IN THE MALE RODENT
}

\author{
H. JACKSON, B. W. FOX AND A. W. CRAIG \\ Department of Experimental Chemotherapy, Christie Hospital, \\ Manchester, 20
}

(Received 26th May, 1961)

Summary. (1) The antifertility effects of a number of simple alkane sulphonic esters have been examined in the male rat by a combination of serial mating of treated animals and histological examination of the testes. The results are compared and contrasted with those obtained with Busulphan (Myleran), dimethylmyleran and various derivatives of ethyleneimine.

(2) A spectrum of results on various stages of spermatogenesis has been obtained, which is difficult to reconcile with a common mode of action due to alkylation of cellular materials.

(3) Certain simple esters produce strikingly different effects. Thus, methylethanesulphonate and methylmethanesulphonate cause early sterility due to interference with spermatids and spermatozoa. Isopropyl alkane sulphonates, on the other hand, cause sterility only after a delay of several weeks.

(4) These esters are effective by mouth and their action is cumulative. Methylmethanesulphonate and methylethanesulphonate in small daily doses produce predictable periods of sterility, according to the dose rate given, which are completely reversible. There is no indication of any action on libido, nor evidence so far of toxic effects from these courses of treatment.

(5) With the series of compounds examined, it has been possible to move the focus of drug action from spermatogonia to spermatids and spermatozoa with reduction of side effects. It is concluded that this work demonstrates that selective interference with fertility in the male is a distinct possibility.

\section{INTRODUCTION}

The main achievement of recent years in the search for substances applicable to the problem of human fertility control has been the development of ovulation inhibitors by Pincus and his co-workers (Pincus, 1958). The successful progress of this work depended upon the development of reliable experimental methods for assessing the ability of synthetic progestational compounds to prevent ovulation - first in rodents and later in human subjects. This approach to fertility control utilized a physiological process to a pharmacological end. 
In the male, there is no comparable process for attack offering a reasonable prospect of success. A test for antifertility activity in the male must rely upon the ability of a substance to produce sterile matings under certain specified conditions. In the light of our experience, a practicable approach in the male could be by chemical interference with testicular and epididymal spermatozoa so that sterile spermatozoa are produced. This can now be accomplished in rodents without interference with the dynamics of spermatogenesis or with libido. The present paper briefly recalls the development of our work on the effects of alkylating agents on rodent fertility and describes the selective antifertility effects we have recently been able to induce in male rats with simple esters.

Although it is 5 years since we first published a report on the ability of the alkylating tumour inhibitor, TEM, to produce sterile phases in male rats (Jackson \& Bock, 1955), there have been no published reports of comparable effects in the male with any other type of chemical agent. The term alkylating agent is applicable to any substance which reacts in such a manner as to introduce into a recipient molecule an alkyl or a substituted alkyl group. Simple examples of alkyl groups are methyl $\left(\mathrm{CH}_{3}-\right)$ and ethyl $\left(\mathrm{CH}_{3} \cdot \mathrm{CH}_{2}-\right)$, but the possible variations in structure are unlimited. These substances fall into a variety of chemical categories which vary widely in both chemical reactivity and biological activity not only from one group to another but also within individual members of a particular type.

The present work forms part of a general project concerned with investigations of the mode of action and metabolism of alkylating agents. Earlier studies utilized substances which were active tumour inhibitors, but we have been able to dissociate tumour inhibitory properties whilst retaining the ability to produce remarkable selective effects on spermatogenesis.

\section{SPERMATOGENESIS IN THE RAT}

Views held on the duration of spermatogenic events in the rat have undergone radical alteration within the past few years. Until recently, a period of 27 days (Shaver \& Mason, 1950) was still considered to be the most likely figure for the development of spermatogonia (Type A) into mature spermatozoa in the testis, and was used in calculations of the duration of various phases of spermatogenesis (Leblond \& Clermont, 1952). Information from studies of the effects of alkylating agents and radiation on rat fertility (Jackson, Craig \& Fox, 1959; Craig, Fox \& Jackson, 1959), recent work on the timing of spermatogenic phases using tritiated thymidine (Clermont, Leblond \& Messier, 1959) and investigations of epididymal dynamics relating to sperm transport (Macmillan \& Harrison, 1955) suggest that the overall time for spermatogenesis is at least 65 days (Table 1). The testicular phase in the rat is known to proceed with great precision requiring about 48 days for completion (Clermont et al., 1959). These results help to account for the clear fertility patterns which we have obtained by applying a serial mating technique to treated male rats. Delay in mating after treatment does not displace the fertility pattern, whilst frequency 
of mating has little effect on the time of appearance or duration of sterile periods after drug treatment.

\section{METHODS}

The experimental procedures have been fully described elsewhere (Bock \& Jackson, 1957; Jackson et al., 1959). As a proliferating system of cells, the spermatogenic epithelium has provided a useful test system for drugs, the effect being measured by the results of individual weekly matings of groups of treated

TABLE 1

DURATION OF SPERMATOGENIC PHASES IN THE RAT*

\begin{tabular}{l|c|c}
\hline \multicolumn{1}{c|}{ Phase } & $\begin{array}{c}\text { Approx. time cells } \\
\text { present }(\text { hr })\end{array}$ & $\begin{array}{c}\text { Days to emission as } \\
\text { mature spermatozoa }\end{array}$ \\
\hline SPERMATOGONIA & & \\
Type A & & \\
Stem cells & $\begin{array}{c}\text { Always present } \\
\text { 2nd generation }\end{array}$ & 52 \\
3rd, & 52 & 63 \\
4th & 52 & 61 \\
Type B & 50 & 59 \\
SPERMATOCYTES & 57 \\
Young, resting primary & 90 & \\
Leptotene & 48 & 55 \\
Zygotene & 17 & \\
Early Pachytene & 107 & \\
Pachytene & 164 & 43 \\
Divisions & 15 & 36 \\
SPERMATIDS & & \\
Golgi phase & 65 & 35 \\
Cap phase & 116 & 33 \\
Acrosome & 107 & 28 \\
Maturation phase & 157 & 23 \\
RELEASE OF SPERMATOZOA & & 15 \\
FROM THE TESTIS \\
via rete testis, epididymis and vas \\
deferens to emergence
\end{tabular}

* Compiled from original data published by Leblond \& Clermont, 1952. Modified on the basis of 48 days for the testicular phase of spermatogenesis and 15 days for transport of spermatozoa through the rete testis, epididymis and vas deferens.

male animals. This simple method, which assesses the biological functionality of the cells liberated from the spermatogenic epithelium, produces fertility patterns which are inversely related in time to the phase of spermatogenesis damaged by the drug used, i.e. effects on spermatozoa appear first, and last of all, those due to interference with spermatogonia. In retrospect, it is surprising that systematic serial weekly matings were not used prior to our own work although, as we now know, its successful application depends upon the fact that in the rat and mouse, spermatogenesis and elimination of spermatozoa proceeds continuously, largely independent of frequency of mating. Histological 
studies are used only as an ancillary technique, since drug sterility is now known to be produced in the absence of obvious histological damage (Bock \& Jackson, 1957; Steinberger, Nelson, Boccabella \& Dixon, 1959). The disadvantages of this technique are that it is tedious and requires large numbers of animals of proven fertility; for these reasons it is not easy to produce adequate doseresponse curves.

The complex system of spermatogenesis should be vulnerable to chemical interference at many stages. In our experience, the male germinal epithelium is by no means necessarily involved in the general toxic effects of chemical agents. The antifertility effects to be described are therefore considered to be selective in character and not merely manifestations of systemic toxicity. Location of the spermatogenic phase susceptible to drug action necessitates accurate knowledge of the timing of spermatogenic events in the testis and the duration of the epididymal phase. Also, that compounds administered do not interfere with the rate of progression of spermatogenesis or the factors determining the rate of passage of liberated spermatozoa through the testis and epididymis.

\section{RESULTS AND DISCUSSION}

\section{DERIVATIVES OF ETHYLENEIMINE}

The earliest experiments in this series were carried out with Tretamine (triethylenemelamine, TEM, Compound II) a derivative of the simple cyclic base, ethyleneimine (Compound I, Text-fig. 1). These ethyleneimine groups in the TEM molecule are responsible for its alkylating properties and mainly determine biological activity, but the nature of the carrier molecule is also important. The effect of TEM on rat fertility has been described elsewhere (Bock \& Jackson, 1957) and recently confirmed (Steinberger et al., 1959). It is a very active substance, small doses soon inducing and maintaining infertility in male rats during treatment and for several weeks after the drug is discontinued. A single dose produced a brief phase of sterility between 20 and 25 days after injection whilst larger doses induce a biphasic fertility pattern (Text-fig. 2), in which the major effect is manifest by sterility for 5 weeks due to interference with spermatids and epididymal spermatozoa. Later, transient sterility develops between 60 and 70 days, in some animals, due to a brief spermatogonial effect (Text-fig. 2). More recently, we have developed an ethyleneimine derivative in which the spermatogonial effect is accentuated so that the biphasic action is well marked (Text-fig. 3).

A variety of ethyleneimine derivatives has been examined and their effects on fertility found to be qualitatively similar (Jackson et al., 1959). According to the dose and the compound used, antifertility effects ranging from the selective types referred to above to complete destruction of the seminiferous epithelium can be achieved, apparently without interference with libido.

ALKANE SULPHONIC ESTERS

These substances are products of the union of an alkane sulphonic acid and an alcohol. Their relation to sulphuric acid is as follows: 
HO. $\mathrm{SO}_{2} \mathrm{OH}$

sulphuric acid

\section{$\mathrm{R} . \mathrm{SO}_{2} . \mathrm{OH}$}

alkane sulphonic acid
R.SO. $\mathrm{SR}^{\prime}$

alkane sulphonic ester

$\left(\mathbf{R}^{\prime}=\right.$ methyl, ethyl etc. $)$

Our earlier work included Busulphan (Myleran, Compound III, Text-fig. 1) possessing two alkylating groups in which the alcohol is butane diol (Jackson et al., 1959). The activity of certain simpler compounds has since been investigated where the alcohol is methanol, ethanol, $n$-propanol and iso-propanol. The corresponding acid is methane sulphonic acid $\left(\mathrm{CH}_{3} \cdot \mathrm{SO}_{2} . \mathrm{OH}\right)$ and in two

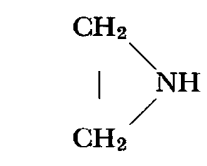

Ethyleneimine I<smiles>CN(C)c1nc(N(C)C)nc(N(C)C)n1</smiles>

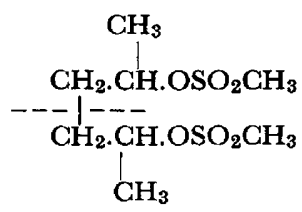

Dimethylbusulphan IV

\author{
Methylmethanesulphonate \\ Ethylmethanesulphonate \\ n-Propylmethanesulphonate \\ iso-Propylmethanesulphonate \\ $\beta$-Chloroethylmethanesulphonate \\ Methylethanesulphonate \\ iso-Propylethanesulphonate
}

TEXT-FIG. 1.

instances ethane sulphonic acid $\left(\mathrm{CH}_{3} \cdot \mathrm{CH}_{2} \cdot \mathrm{SO}_{2} \cdot \mathrm{OH}\right)$. The formulae for these esters are listed in Text-fig. 1 (Compounds $\mathrm{V}$ to XI). The use of simpler substances with biological activity enables correlation between chemical structure and biological activity to be more easily recognized.

The effects of Busulphan have been mentioned elsewhere (Jackson et al., 1959; Jackson, 1960). Current views ascribe its biological effects to reaction with chromosomal material. Its delayed antifertility effect (Text-fig. 4), due apparently to selective interference with spermatogonial development (see 


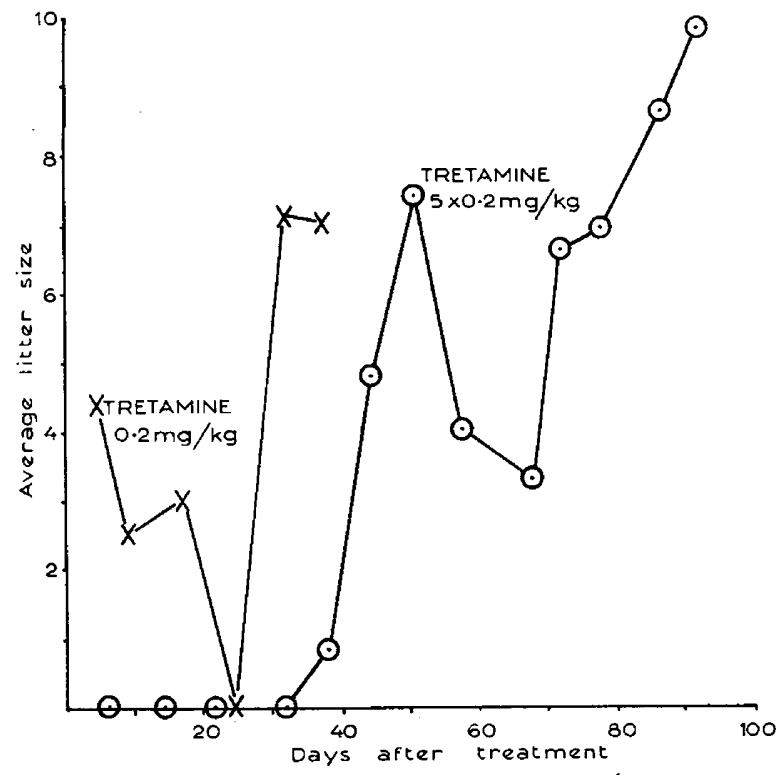

TexT-FIG. 2. A single dose of Tretamine $(0.2 \mathrm{mg} / \mathrm{kg}$, intraperitoneal $)$ produced transient sterility in all animals during the 4 th week. Five such doses on consecutive days caused sterility for 35 days, followed by recovery of normal fertility. A second phase of sterility developed in some animals 60 to 70 days after treatment as a result of spermatogonial damage. The result was overall subfertility in the group during this time.

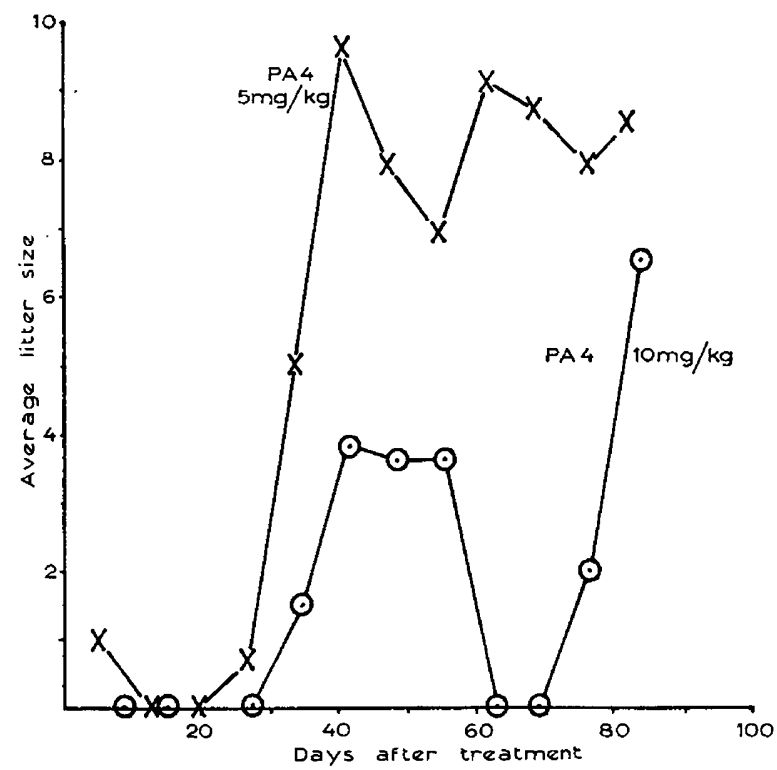

TEXT-FIG. 3. The smaller dose $(5 \mathrm{mg} / \mathrm{kg}$, intraperitoneal $)$ of this tetrafunctional derivative of ethyleneimine produced sterility between 10 to 20 days only. The larger dose caused infertility for 35 days (like Tretamine) with an enhanced spermatogonial effect resulting in sterility between 60 and 70 days. 
Table 1), is not easy to explain on this basis. The action is also cumulative since divided doses are as effective as single injections and the dose response curve is steep (Table 2). The antifertility effect of this drug is very different from that of derivatives of ethyleneimine since the latter interfere predominantly with later phases of spermatogenesis. Dimethylbusulphan (Compound IV) produced marked subfertility during the first 3 weeks after a single dose, in addition to the later Busulphan-type sterile phases (Text-fig. 4 and Table 2). This initial antifertility effect suggested that interference with late stages of spermatogenesis was also possible with this type of compound.

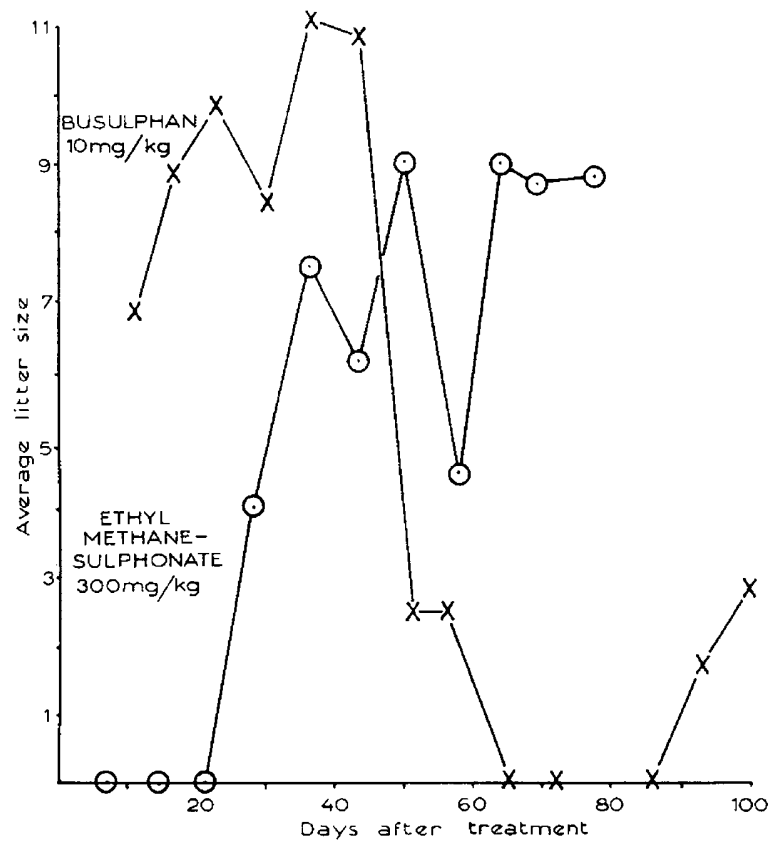

TExT-Fig. 4. A single dose of Busulphan produced a delayed and prolonged antifertility action due to selective interference with early phases of spermatogenesis. Ethylmethanesulphonate, however, caused sterility for 4 weeks from treatment followed by recovery, with no subsequent loss of fertility.

$\beta$-Chloroethylmethanesulphonate (Compound IX, Text-fig. 1) was developed, like Busulphan, as a possible tumour inhibitor with two alkylating groups (Ross, 1956). Although much less potent than Busulphan, it effectively inhibited the Walker carcinoma but, in similar dosage produced a different antifertility effect (Table 3 ). Marked subfertility occurred in the first 3 weeks after treatment, followed by complete recovery of fertility, recalling the early part of the antifertility pattern after dimethylbusulphan (Table 2). There was, however, no notable later effect on fertility indicative of spermatogonial damage. This experiment suggested the possibility of selective attack by simple alkane sulphonic esters limited to later stages of spermatogenesis, which had not been achieved with the ethyleneimine group of alkylating agents.

The next stage, therefore, was the replacement of the chlorine atom of 


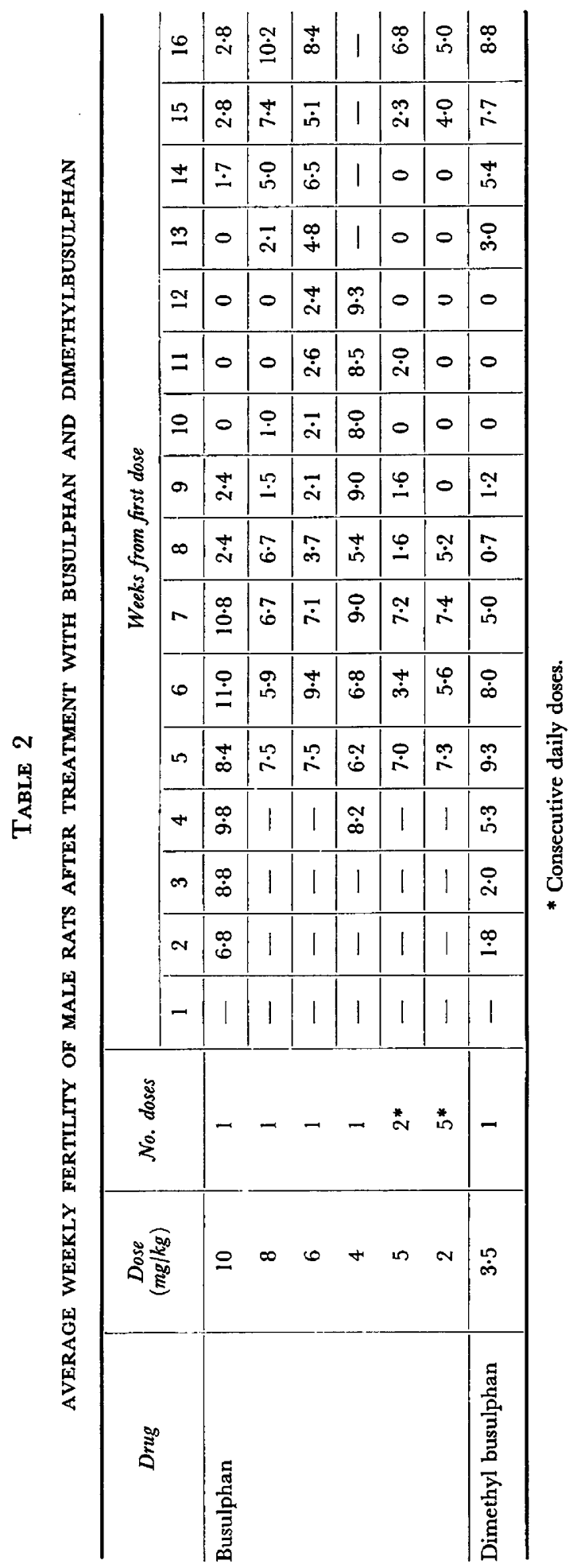




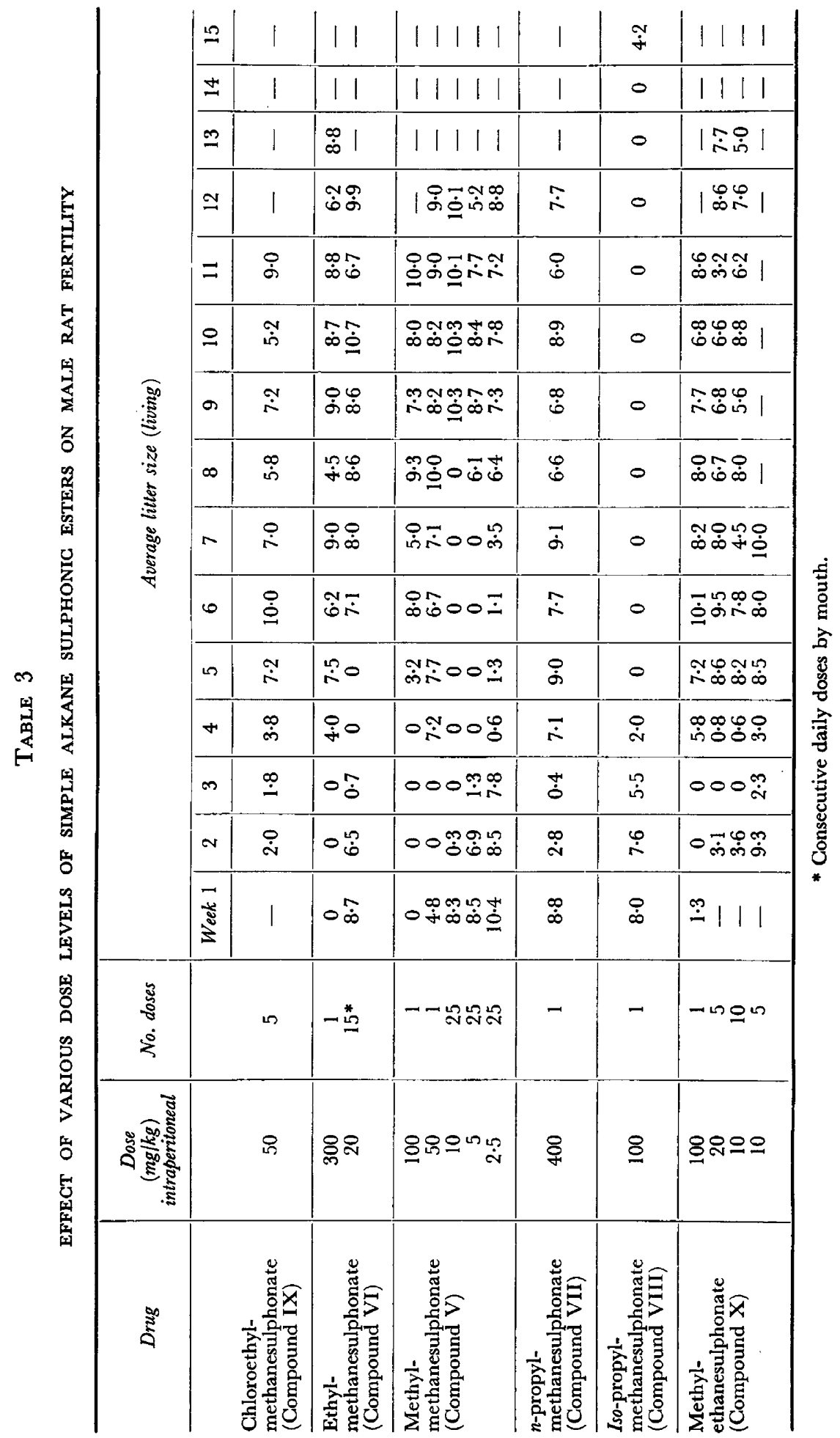


chloroethylmethanesulphonate (Compound IX) by hydrogen with the formation of ethylmethanesulphonate (Compound VI, Text-fig. 1). A single injection of $100 \mathrm{mg} / \mathrm{kg}$ produced general subfertility during the first 3 weeks but a larger dose $(300 \mathrm{mg} / \mathrm{kg})$ was readily tolerated and caused complete sterility for the same period (Table 3 and Text-fig. 4). Normal fertility was regained by the 5th week and persisted, apart from subfertility in the 8th week - a possible spermatogonial effect. The duration of the initial sterile phase is 2 weeks shorter than that following TEM treatment (five daily doses, $0.2 \mathrm{mg} / \mathrm{kg}$ or one dose, $1 \mathrm{mg} / \mathrm{kg}$; compare Text-fig. 2). If alkylation is the mode of action of ethylmethane-

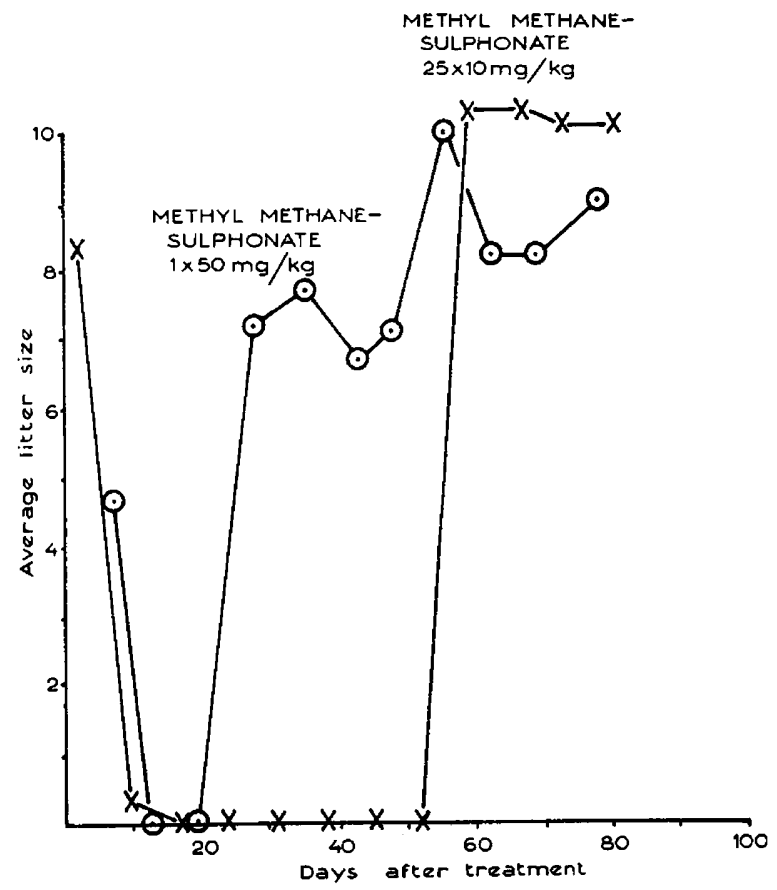

TExT-FIG. 5. A single injection of methylmethanesulphonate $(50 \mathrm{mg} / \mathrm{kg}$, intraperitoneal) caused sterility during Weeks 2 and 3 followed by rapid recovery of normal fertility which was maintained. A series of injections, during which successive pairings were carried out as usual, resulted in the development of sterility during the 2nd week. This state persisted throughout treatment and for about 3 weeks after the last dose when rapid restoration of normal fertility ensued.

sulphonate, the 'ethyl' group should be introduced into recipient molecules of the cell.

Methylmethanesulphonate (Compound V, Text-fig. 1), the simplest member of this series, should by its alkylation mechanism introduce the 'methyl' group into biological material. It proved to be more potent than ethylmethanesulphonate. A single intraperitoneal dose of $100 \mathrm{mg} / \mathrm{kg}$ caused sterility for 28 days, after which normal fertility rapidly returned and was maintained. One-half this dose $(50 \mathrm{mg} / \mathrm{kg})$ produced complete sterility in Weeks 2 and 3 after the dose (Table 3 and Text-fig. 5). The first inseminations in this experiment (5 to 7 days) yielded litters approaching normal size, whilst matings after the sterile 
phase also resulted in completely normal litters (Table 4 ). There was no reduction in litter size in subsequent pairings suggestive of any action on spermatogonia. The effect of increasing the length of the carbon chain of the alkylating group was tested by administering $n$-propylmethanesulphonate (Compound VIII, Text-fig. 1). Its action resembled that of the other esters of methane sulphonic acid referred to above except that it was less active. A dose of 400 $\mathrm{mg} / \mathrm{kg}$ was readily tolerated and caused marked subfertility during the 2 nd and 3rd weeks after treatment (Table 3 and Text-fig. 6).

In order to examine the possible influence of the acidic part of these esters, methylethanesulphonate (Compound X, Text-fig. 1) was examined. Here the

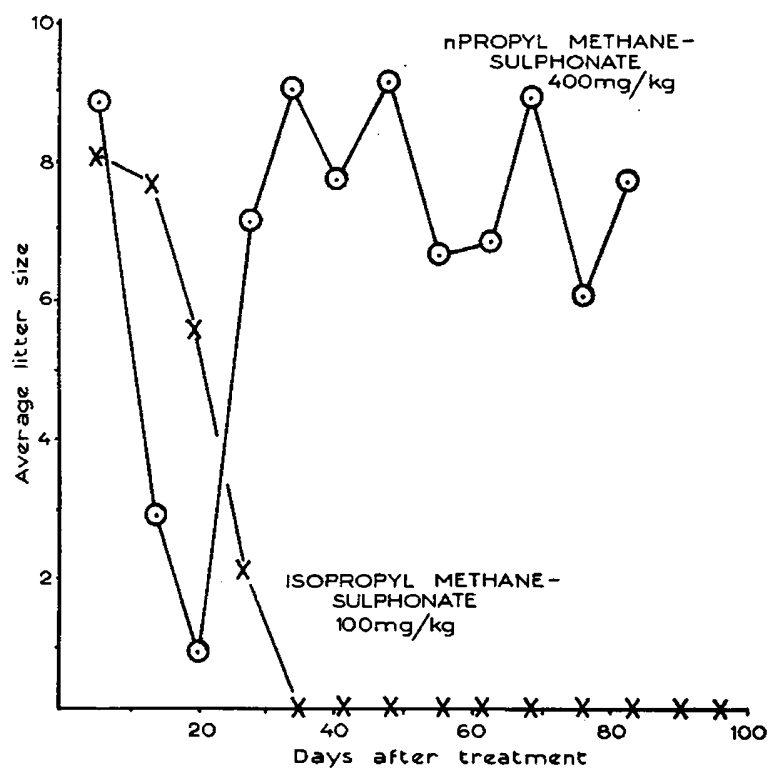

TexT-FIG. 6. $n$-Propylmethanesulphonate caused marked subfertility in Weeks 2 and 3 after the dose, resembling, although less effective than, the methyl and ethyl esters (Table 3 and Text-fig. 5). Iso-Propylmethanesulphonate had a quite different effect, inducing prolonged sterility from the 6 th week onwards (see also Table 3).

alkylating group is again 'methyl'. A single dose of $100 \mathrm{mg} / \mathrm{kg}$ also induced sterility during Weeks 2 and 3 after treatment (Table 3 ) so that evidently this variation in the sulphonic acid structure was unimportant. The duration of the sterile period after a single dose of methylmethanesulphonate $(50 \mathrm{mg} / \mathrm{kg})$ and methylethanesulphonate $(100 \mathrm{mg} / \mathrm{kg})$ demonstrates that spermatozoa are not uniformly affected through the epididymal pathway; those in its terminal part are not so readily damaged. From the rapid termination of sterility in these experiments, it appears that cells become sensitive to these chemicals at a particular phase of spermatogenesis. This sudden development of susceptibility is interesting and is not easy to reconcile with a general mode of action due to alkylation of nuclear material in cells. 


\section{GUMULATIVE EFFEGTS OF METHYLETHANESULPHONATE AND METHYLMETHANESULPHONATE}

The action of Busulphan on spermatogonia has been shown to be cumulative, since divided doses can produce similar effects to a single dose (Table 2). It was of interest to investigate whether the simple monofunctional esters referred to above produced cumulative effects at the other end of the spermatogenic pathway. This proved to be the case (Table 3 ). Thus, divided doses of methyl-

TABLE 4

EFFECT OF METHYLMETHANESULPHONATE ON MALE RAT FERTILITY

\begin{tabular}{|c|c|c|c|}
\hline Treatment & $\begin{array}{l}\text { Time range of } \\
\text { inseminations } \\
\text { (days from } 1 \text { st dose) }\end{array}$ & Individual litter sizes & $\begin{array}{l}\text { Mean litter } \\
\text { size }\end{array}$ \\
\hline $\begin{array}{l}\text { One dose } 50 \mathrm{mg} / \mathrm{kg} \text {, } \\
\text { intraperitoneal aq. on } \\
\text { Day } 0 .\end{array}$ & $\begin{array}{l}5 \text { to } 7 \\
12 \text { to } 14 \\
19 \text { to } 20 \\
25 \text { to } 27 \\
32 \text { to } 34 \\
39 \text { to } 42 \\
46 \text { to } 49 \\
53 \text { to } 56 \\
58 \text { to } 62 \\
65 \text { to } 68 \\
74 \\
79 \text { to } 82\end{array}$ & $\begin{array}{l}7,0,2,8,7,5(1), 6 . \\
0,0,0,0,0,0,0 . \\
0,0,0,0,0,0,0 . \\
8(1), 12,8,8(1), 8,0,9 . \\
9(2), 6,7,9,8,11,7(1) \\
14,0,8(1), 7,2,0,11(1) \\
6,0,9,9,10,8,9(1) \\
12,6,11,12,10,9,10 . \\
10,0,11(1), 8,10,9,11 . \\
11,7,13(7), 10,13,-, 11 . \\
10,10(2), 11,12,10,6(2), 8 . \\
12,8(1), 5,10,10,8,12(1) .\end{array}$ & $\begin{array}{l}4 \cdot 9 \\
0 \\
0 \\
8 \cdot 5 \\
10 \cdot 8 \\
8 \cdot 0 \\
7 \cdot 1 \\
10 \cdot 0 \\
8 \cdot 3 \\
8 \cdot 3 \\
9 \cdot 0 \\
9 \cdot 0\end{array}$ \\
\hline \multirow{2}{*}{$\begin{array}{l}\text { Twenty-five doses } \\
10 \mathrm{mg} / \mathrm{kg} \\
\text { intraperitoneal aq. } \\
\text { five doses } / \mathrm{wk} \\
\text { for } 5 \text { weeks. }\end{array}$} & $\begin{array}{c}\text { Treatment } \\
0 \text { to } 4 \\
8 \text { to } 11 \\
16 \text { to } 18 \\
22 \text { to } 25 \\
29 \text { to } 32 \\
\text { Treatment ended }\end{array}$ & $\begin{array}{l}8,11,11,8,8,9,3 \\
0,0,0,2,0,0,0 . \\
0,0,0,0,0,0,0 . \\
0,0,0,0,0,0,0 . \\
0,0,0,0,0,0,0 .\end{array}$ & $\begin{array}{l}8 \cdot 3 \\
0 \cdot 3 \\
0 \\
0 \\
0\end{array}$ \\
\hline & $\begin{array}{l}37 \text { to } 39 \\
44 \text { to } 46 \\
50 \text { to } 53 \\
57 \text { to } 60 \\
64 \text { to } 67 \\
72 \text { to } 73 \\
78 \text { to } 81\end{array}$ & $\begin{array}{l}0,0,0,0,0,0,0 . \\
0,0,0,0,0,0,0 . \\
0,0,0,0,0,0,0 . \\
13,11,13,10,7,11(1), 8 . \\
10,13,10,11,9,10,11(2) \\
13,10,14,6,13,{ }^{*}, 5 . \\
12,6,12,11,7,9,6 .\end{array}$ & $\begin{array}{c}0 \\
0 \\
0 \\
10 \cdot 3 \\
10.3 \\
10 \cdot 1 \\
10 \cdot 1\end{array}$ \\
\hline
\end{tabular}

\footnotetext{
* Litter destroyed by mother.
}

Fertility data are presented for individual rats from two experiments using methylmethanesulphonate: (1) a single dose (50 mg/kg, intraperitoneal in water) to a group of eight fertile male rats; (2) a course of twenty-five doses (each $10 \mathrm{mg} / \mathrm{kg}$ intraperitoneal in water) in 32 days to seven fertile male rats. In the latter experiment, pairing of the rats commenced on the day of the first dose. The numbers in parentheses refer to offspring born dead and are comparable to control values. Ciphers in italic indicate pairings in which insemination was not detected.

ethanesulphonate (five daily doses $20 \mathrm{mg} / \mathrm{kg}$ or ten daily doses, $10 \mathrm{mg} / \mathrm{kg}$ ) produced similar antifertility patterns to the single total dose (100 $\mathrm{mg} / \mathrm{kg})$. Since methylmethanesulphonate was more potent, it was decided to investigate the effect of more prolonged treatment at low dose levels. Daily doses were given to male rats over a period of nearly 5 weeks (twenty-five injections in all, the last on Day 32). Treatment was thus given during periods of mating, a departure from the usual procedure. Since litter sizes were normal from matings 
occurring during the first few days (Tables 3 and 4), even at the highest dose rate used $(10 \mathrm{mg} / \mathrm{kg})$, the possibility may be discounted that drug excreted via the kidney and persisting in the urogenital pathway exerted a spermicidal action. With $10 \mathrm{mg} / \mathrm{kg}$ daily, after the first fertile mating, all animals were rendered sterile for about 45 days ( 7 consecutive weeks of mating) so that infertility persisted up to about 21 days from the last dose (Table 4). The next and succeeding inseminations yielded litters above the normal average. A similar course of treatment using $5 \mathrm{mg} / \mathrm{kg}$ delayed the onset of sterility and shortened its duration to 4 weeks, whilst $2.5 \mathrm{mg} / \mathrm{kg}$ did not induce total sterility

TABLE 5

STERILE PHASES IN INDIVIDUAL ANIMALS AFTER TREATMENT WITH SINGLE DOSES OF ALKANE SULPHONIC ESTERS

\begin{tabular}{|c|c|c|}
\hline Compound and treatment & Animal No. & $\begin{array}{c}\text { Duration of sterility } \\
\text { (days from treatment, both inclusive) }\end{array}$ \\
\hline $\begin{array}{c}\text { Busulphan } \\
6 \mathrm{mg} / \mathrm{kg} \text {, intraperitoneal }\end{array}$ & $\begin{array}{l}1 \\
2 \\
3 \\
4 \\
5 \\
6 \\
7 \\
8 \\
9\end{array}$ & $\begin{array}{l}68 \text { to } 97 \\
55 \text { to } 91 \\
76 \text { to } 85 \\
63 \text { to } 96 \\
76 \text { to } 88 \\
48 \text { to } 83 \\
61 \text { to } 96 \\
62 \text { to } 93 \\
64 \text { to } 88\end{array}$ \\
\hline $\begin{array}{l}\text { Methylethanesulphonate } \\
100 \mathrm{mg} / \mathrm{kg} \text {, intraperitoneal }\end{array}$ & $\begin{array}{l}1 \\
2 \\
3 \\
4 \\
5 \\
6 \\
7 \\
8\end{array}$ & $\begin{array}{r}11 \text { to } 20 \\
7 \text { to } 20 \\
7 \text { to } 20 \\
14 \text { to } 20 \\
0 \text { to } 25 \\
4 \text { to } 31 \\
0 \text { to } 20 \\
0 \text { to } 20\end{array}$ \\
\hline $\begin{array}{l}\text { Methylmethanesulphonate } \\
50 \mathrm{mg} / \mathrm{kg} \text {, intraperitoneal }\end{array}$ & $\begin{array}{l}1 \\
2 \\
3 \\
4 \\
5 \\
6 \\
7\end{array}$ & $\begin{array}{r}12 \text { to } 19 \\
5 \text { to } 19 \\
14 \text { to } 19 \\
13 \text { to } 19 \\
14 \text { to } 19 \\
14 \text { to } 26 \\
13 \text { to } 20\end{array}$ \\
\hline
\end{tabular}

(Table 3). Instead, marked subfertility developed in the 4th week from the first injection and also persisted for 4 weeks. Thus the minimal daily dose required to produce sterility in all animals lies between 2.5 and $5 \mathrm{mg} / \mathrm{kg}$.

Experiments with single doses of methylethanesulphonate and methylmethanesulphonate demonstrate clearly that cells due to emerge as mature spermatozoa 2 to 3 weeks later (or essential mechanisms associated with their development during this period) are most susceptible to these compounds (Table 3). According to current views on the timing of spermatogenic events in the rat, the target cells are morphologically mature spermatozoa in the testes and upper reaches of the epididymis (Table 1). However, this statement may 
need some revision when the duration of the epididymal phase is known more accurately. The rapid return of normal fertility after single doses of these esters suggests that the onset of susceptibility during spermatogenesis is quite sharp. Sterility after divided doses should therefore persist for about 3 weeks after discontinuation of treatment. The results in Table 3 are reasonably consistent with this view. An examination of the sterile phases for individual animals after treatment with methylmethanesulphonate and methylethanesulphonate reveals that in some animals the onset of sterility is rapid (Table 5), i.e. spermatozoa are affected throughout the entire epididymal pathway. However, the return of fertility is consistently sharp and predictable in contrast to the more variable period of sterility which follows the spermatogonial induced damage of Busulphan. It is important to note that in all experiments with methylmethanesulphonate, ethylmethanesulphonate and methylethanesulphonate, inseminations and sperm motility appeared normal during the sterile phases, recalling the action of Tretamine (Bock \& Jackson, 1957; Steinberger et al., 1959).

These esters of alkane sulphonic acids are also active orally in aqueous solution. Thus, fifteen consecutive daily doses of ethylmethanesulphonate $(20 \mathrm{mg} / \mathrm{kg})$ by mouth produced a similar effect to a single injected dose (300 $\mathrm{mg} / \mathrm{kg}$ ), except for some delay in the onset of the sterility (Table 3 ).

Since ethylmethanesulphonate (Compound VI) corresponds to 'one-half' of the Busulphan molecule (compare Compound VI with Compound III, Text-fig. 1), a logical development was to test 'one-half' of dimethylbusulphan, namely, isopropylmethanesulphonate (Compound VIII, compare Compound IV, Text-fig. 1). Alkylation by this substance will introduce the 'isopropyl' group. The antifertility pattern after a single injection of $100 \mathrm{mg} / \mathrm{kg}$ was strikingly different from that produced by the other simple esters (Compounds $\mathrm{V}$, VI, VII, IX, X.) There appeared to be no effect on spermatozoa since animals remained fertile for 2 to 3 weeks, but thereafter fertility declined and all were sterile by the 35th day (Table 3 and Text-fig. 6). This is about the time after which fertility begins to return following TeM treatment (Text-fig. 2). A smaller dose of isopropylmethanesulphonate $(50 \mathrm{mg} / \mathrm{kg})$ did not produce a phase of complete sterility in the group of animals, although the fertility curve showed two regions of marked subfertility with minima about 35 days and 65 days. The effect of this ester is also cumulative and although the compound has a short chemical half-life in aqueous solution (about $13 \mathrm{~min}$ at $37^{\circ} \mathrm{C}$ ) it is, nevertheless, equally active in divided doses. Thus, ten daily doses of $10 \mathrm{mg} / \mathrm{kg}$ gives the same result as a single dose of $100 \mathrm{mg} / \mathrm{kg}$. Isopropylethanesulphonate (Compound XI, Text-fig. $1 ; 100 \mathrm{mg} / \mathrm{kg}$ ) produced a similar antifertility pattern to isopropylmethanesulphonate.

This surprising alteration in pattern of action on fertility is undoubtedly due to the 'isopropyl' group since $n$-propylmethanesulphonate resembled the methyl and ethyl esters in its action as was pointed out earlier (Table 3 and Text-fig. 6). Other related compounds are being prepared and tested with a view to correlating chemical structure with effects on spermatogenesis and spermatozoa. 
HISTOLOGICAL GHANGES IN THE TESTIS AFTER ADMINISTRATION OF ALKANE SULPHONIC ESTERS

The fertility patterns after administration of methylethanesulphonate and methylmethanesulphonate, especially in small daily doses, suggests that their action is practically confined to spermatozoa and late spermatids. We do not know, however, how far the normal average sperm count in the rat can be reduced but still permit the production of normal size litters. No reliable method is available for measuring the spermatozoa output in small rodents so that it is important to carry out serial histological examinations of the testes of treated rats in order to assess whether damage to earlier phases of spermatogenesis has occurred in spite of evidence to the contrary from fertility data. Without a detailed analysis of the cell population of the seminiferous epithelium, minor degrees of damage may well be overlooked. Investigation of this possibility is a formidable operation, which is being undertaken in certain instances.

The purpose of the selected number of histological pictures presented is to demonstrate that fertility changes can be correlated with changes in testis histology when damage has been inflicted upon early types of spermatogenic cell. Since one Type A spermatogonium produces ninety-six spermatozoa, the consequence of damage to this and similar cells will result in an amplified pharmacological effect. For simplicity of presentation, reference will be made to a particular tubule section. This shows one of the many possible cell combinations resulting from the concurrent development of four distinct generations of spermatogenic cells within any tubule segment. The stage chosen represents that following the last spermatogonial division. The four generations of cell are readily seen (Pl. I, Fig. 1). The inner-most layer is composed of morphologically mature spermatozoa about to be shed from the epithelium. Next to these is a broad zone of spermatids about four cells deep, surrounded in turn by a single ring of large spermatocytes in preparation for meiosis. The peripheral generation are the small, resting spermatocytes ('pre-spermatocytes') recently formed from Type B spermatogonia and interspersed with large, pale Sertoli cells. One or two Type A spermatogonia can sometimes be found in this section.

This 'normal' state of affairs prevails about 12 days after a single dose of Busulphan (10 mg/kg, Pl. 1, Fig. 3) and 2 days after an injection of isopropylmethanesulphonate $(100 \mathrm{mg} / \mathrm{kg}$, Pl. 1, Fig. 4). Both compounds have, nevertheless, already interfered with spermatogonial development. Twenty days after Busulphan treatment, the histological picture corresponds approximately to that 10 days after the isopropyl compound (PI. 2, Figs. 5 and 6, respectively). The peripheral layer of pre-spermatocytes has moved on to large spermatocytes, but has not been replaced owing to some kind of spermatogonial block. The epithelium now consists of large spermatocytes, spermatids and spermatozoa, i.e. a process of depletion by maturation is in progress. By 30 days after the Busulphan injection, virtually all spermatocytes have developed into spermatids, so that spermatids and spermatozoa constitute the epithelium (Pl. 2, Fig. 7); this stage is attained about 20 days in the isopropylmethanesulphonate series (Pl. 2, Fig. 8). Depletion is practically complete 39 days after Busulphan and 30 days after isopropylmethanesulphonate, so that the epithelium in these 
sections consists of a few residual spermatozoa and peripheral Sertoli cells (Pl. 3, Figs. 9 and 10). However, in both cases there is now evidence of renewed spermatogonial activity, which will eventually result in repopulation of the tubules and recovery of fertility.

After administration of these two compounds, there is obviously a difference in the time required for depletion by maturation to occur. Both interfere with spermatogonial development but Busulphan apparently acts more selectively upon early spermatogonia; isopropylmethanesulphonate not only affects spermatogonia so that no new spermatocytes are formed but also damages spermatocytes and probably spermatids. These latter cells continue to develop but the spermatozoa produced are infertile. Hence, sterility commences about 35 days after isopropylmethanesulphonate compared with 50 to 60 days after Busulphan. With a smaller dose of isopropylmethanesulphonate $(50 \mathrm{mg} / \mathrm{kg}$ ), the histological sequence up to about 20 days is similar to that following the larger dose (Pl. 3, Fig. 11). However, there is also obvious evidence of spermatogonial repopulation and, at 26 days, regeneration is rapidly under way (PI. 3, Fig. 12). Spermatogonial damage of this kind is thus readily recognized histologically.

The appearance 30 days after treatment with methylethanesulphonate $(100 \mathrm{mg} / \mathrm{kg}$ ) is normal (PI. I, Fig. 2), and correlates with the antifertility pattern, indicating the absence of a significant spermatogonial effect.

\section{SIDE EFFEGTS}

Since the substances under discussion are alkylating agents, although of varying stability and presumably reactivity, evidence of toxic effects must be sought for with great care. The search for undesirable side actions requires study in a variety of experimental animals, especially with regard to damage to other spermatogenic cells, normal proliferating systems of other types (e.g. haematopoiesis) and assessments of the risks of carcinogenesis and possible genetic damage. At the present stage of investigations, it is only possible to make a few brief comments. Weight loss follows administration of large single doses of the alkane sulphonic esters, but small divided doses, which still produce marked antifertility effects, do not cause significant weight change. Compounds like Tretamine and Busulphan are tumour inhibitors and induce marked depression of the white cell count, so that the action of the simple esters on leucopoiesis is being examined. Since Busulphan and its dimethyl derivative cause a selective granulocytopenia, the lymphocytopenia following administration of high doses of methyl and ethyl esters of alkane sulphonic esters was unexpected. It differs from the lymphopenia following treatment with nitrogen mustards and ethyleneimine derivatives, being more rapid in onset, transient and not associated with granuloctye depression. Our results suggest that it may be due to some effect on mature lymphocytes rather than any serious action on earlier phases of haemopoiesis. Divided doses of these compounds do not cause notable change in the peripheral white cell count, i.e. the effects on the blood appear not to be cumulative, in contrast to the consequence on spermatogenesis of similar treatment. Up to the present time, there has been no sign of carcinogenicity 
although a deliberate search for this serious hazard must be made. Offspring born during the transitional phases from fertility to sterility, and vice versa, have been kept and reared to normal adults, whilst normal size, healthy litters have resulted from inbreeding these animals. These tentative results suggest that the treatments given may not cause hereditary damage to the germinal tissues, but it would be unwise to place undue weight on this preliminary data.

\section{CONCLUSION}

Administration of simple esters of methane and ethane sulphonic acids produces antifertility patterns (Text-fig. 7) which, broadly speaking, fall into three types

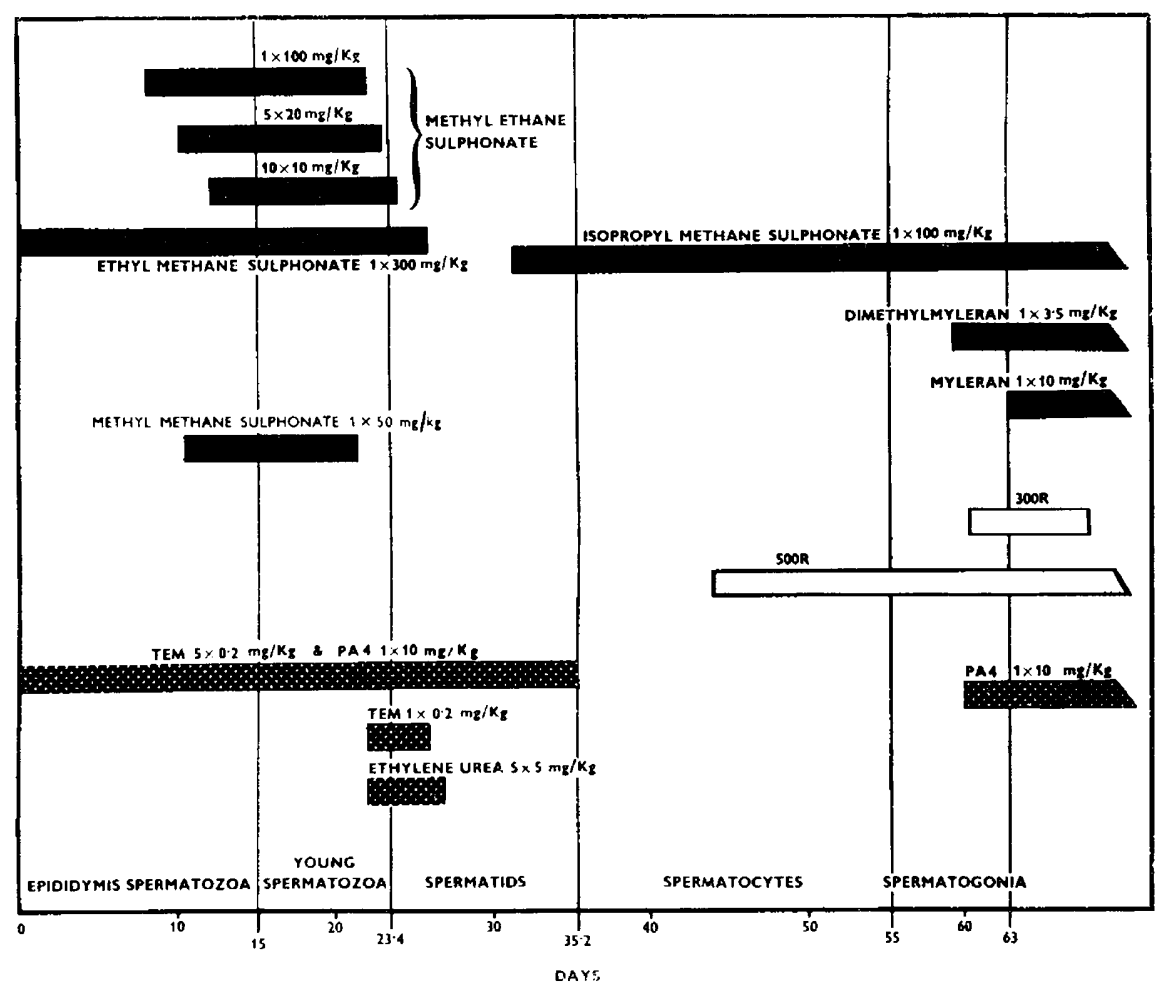

TEXT-FIG. 7. Diagrammatic representation of the various sterile phases which can be induced in the male rat by various alkylating agents. The periods are shown in relation to the stages in spermatogenesis with which the compounds interfere.

dependent upon interference with (a) early phases of spermatogenesis (e.g. spermatogonia), (b) late phases (spermatids, spermatozoa) or (c) a combination of both. Individual variation in susceptibility to these compounds is reflected to a greater extent in the effects on early germinal cells than when later phases of spermatogenesis are involved (Table 5). The latter is a favourable situation in regard to the possibility of fertility control in the male by interference with developing or mature spermatozoa. In general, a considerable and surprising degree of dissociation of pharmacological activity against different phases of spermatogenesis has been achieved.

It is interesting to consider how far the most promising compound in our 
series represents a step towards the development of an antifertility substance for use in the male. The chemical structure is simple, and the compound easily and cheaply prepared. In the rat, it is rapid in action, $100 \%$ effective and active by the oral route. Fully reversible and predictable periods of sterility can be produced in these animals by small, divided doses which are tolerated without manifestations of toxicity. The action is exerted directly upon spermatozoa and spermatids, apparently without interference with sperm production or turnover. There is no evidence whatever to suggest an effect upon libido.

The most important outcome of the present work is the demonstration that selective attack on various stages of the long complex process of spermatogenesis is practicable. The enhancement of action on spermatozoa with reduction of side effects is encouraging, although the fact that these substances are alkylating agents emphasizes the need for great care in assessing toxicity, especially the risk of carcinogenesis or damage to genetic material. It seems likely that future work will result in the discovery of other compounds with greater specificity of action.

The mode of action of the present substances is being investigated since this may lead to other promising methods of approach in the control of male fertility, whilst facilitating investigations of the physiological and biochemical mechanisms involved.

\section{REFERENCES}

Bock, M. \& Jackson, H. (1957) The action of triethylenemelamine on the fertility of male rats. Brit. $\mathcal{F}$. Pharmacol. 12, 1.

Clermont, Y., Leblond, C. P. \& Messier, B. (1959) Durée du cycle de l'épithélium séminal du rat. Arch. Anat. micr. Morph. exp. 48, 37.

CRAIG, A. W., Fox, B. W. \& Jackson, H. (1959) The effect of irradiation on fertility of the male rat. Brit. F. Radiol. 32, 390.

Jackson, H. (1960) Antifertility substances. Pharmaceutical Fournal, February 20.

Jackson, H. \& Bock, M. (1955) The effect of triethylenemelamine on the fertility of rats. Nature, Lond. $175,1037$.

Jackson, H., Craig, A. W. \& Fox, B. W. (1959) The effect of alkylating agents on male rat fertility. Brit. F. Pharmacol. 14, 149.

Leblond, C. P. \& Clermont, Y. (1952) Spermiogenesis of rat, mouse, hamster and guinea-pig as revealed by the 'periodic acid-fuchsin sulfurous acid' technique. Amer. F. Anat. 90, 167.

Magmillan, E. W. \& Harrison, R. G. (1955) The rate of passage of radio-opaque medium along the ductus epididymis of the rat. Studies on Fertility, 7, 35 .

Pincus, G. (1958) Fertility control by oral medication. Studies on Fertility, 10, 3.

Ross, W. C. J. (1956) Cytotoxic sulphonic esters and related compounds. Ann. Rep. Brit. Emp. Campaign, p. 10.

Shaver, S. L. \& Mason, R. E. (1950) Selective testicular damage in rats due to X-rays. Anat. Rec. Suppl. 106, 80.

Steingerger, E., Nelson, W. O., Boccabella, A. \& Dixon, W. J. (1959) A radiomimetic effect of triethylenemelamine on reproduction in the male rat. Endocrinology, 65, 40.

\section{DESGRIPTION OF PLATES}

\section{PLATE 1}

Fig. 1. Section of normal rat testis tubule.

FIG. 2. Thirty days after treatment with methylethanesulphonate $(100 \mathrm{mg} / \mathrm{kg})$. Normal appearance.

FIG. 3. Twelve days after Busulphan $(10 \mathrm{mg} / \mathrm{kg})$. Normal appearance.

FIG. 4. Two days after isopropylmethanesulphonate $(100 \mathrm{mg} / \mathrm{kg})$. Normal appearance. 


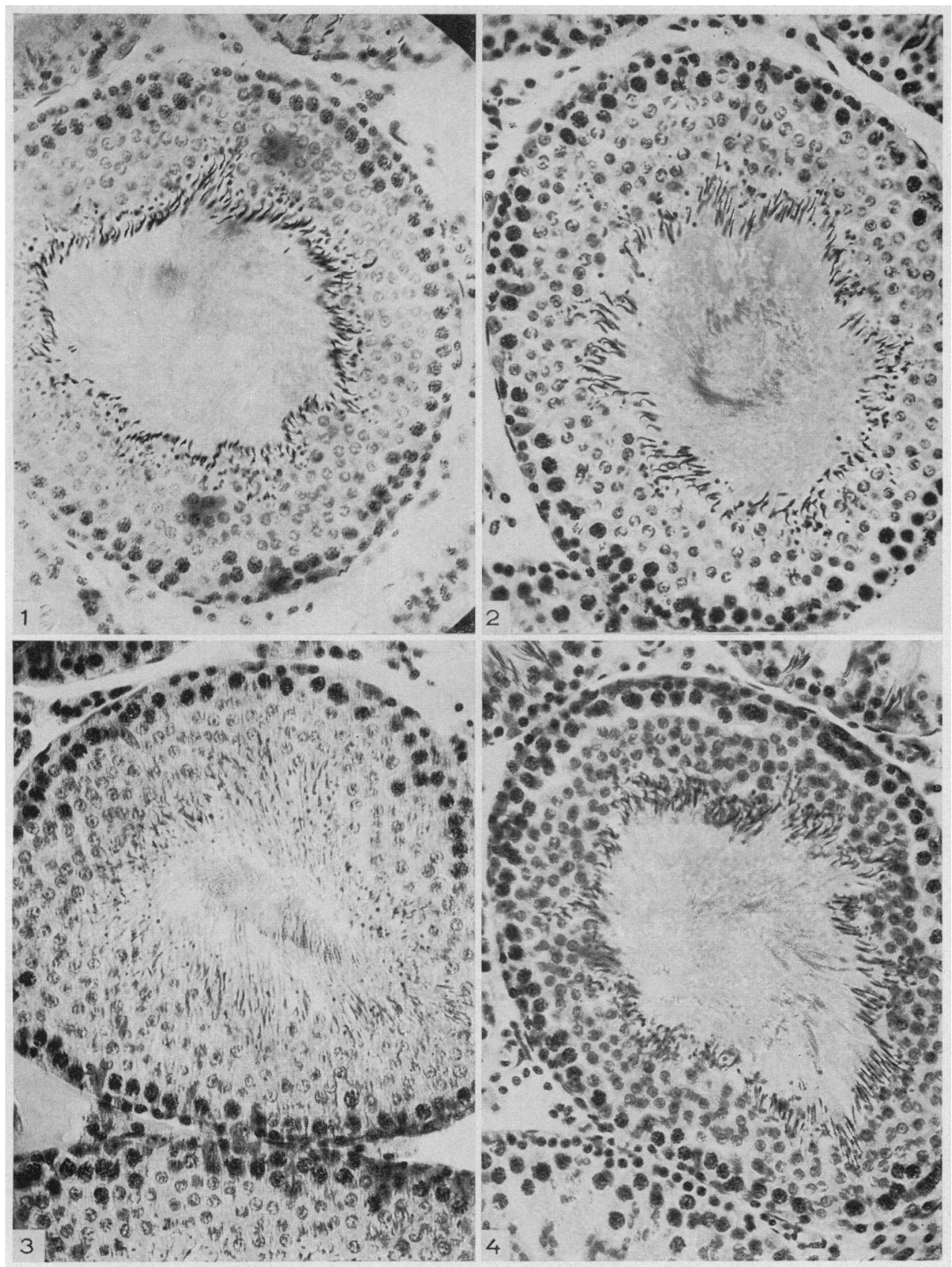

(Facing p. (464) 
PLATE 2

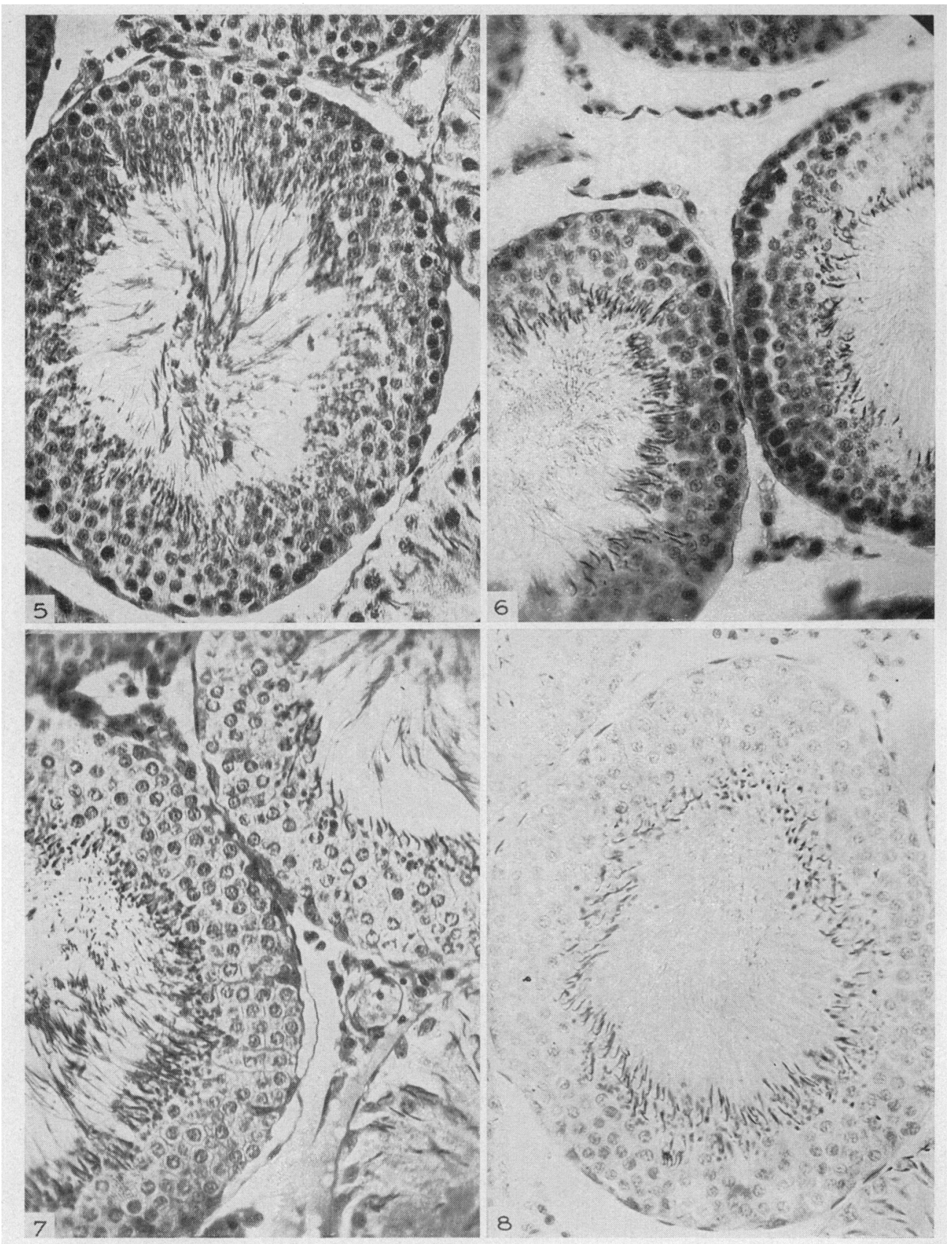


PLATE 3

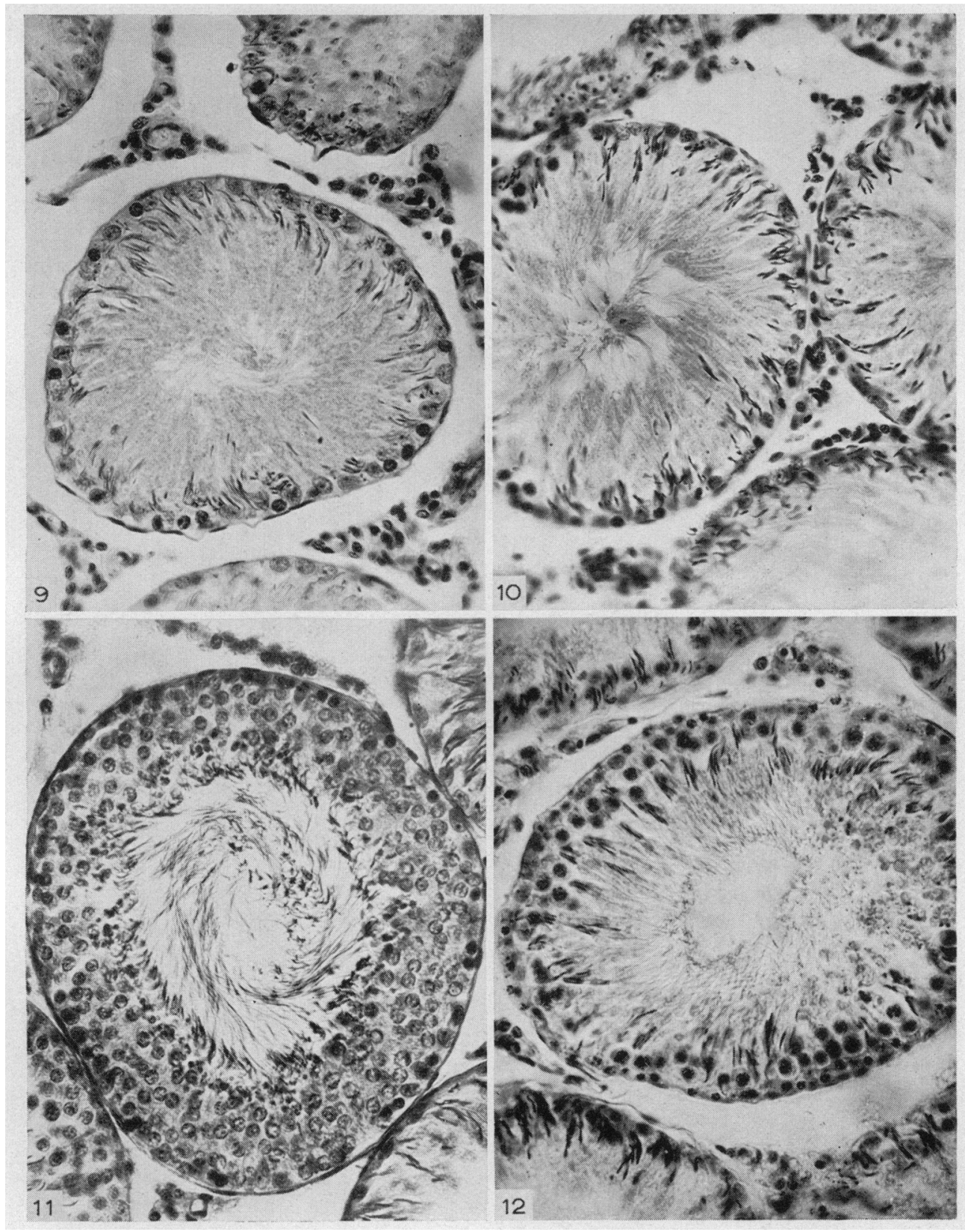


PLATE 2

Fig. 5. Testis tubule 19 days after Busulphan $(10 \mathrm{mg} / \mathrm{kg})$. No resting primary spermatocytes. The peripheral layer of cells are pre-meiotic spermatocytes.

Fig. 6. Ten days after isopropylmethanesulphonate $(100 \mathrm{mg} / \mathrm{kg})$. Few resting primary spermatocytes. Otherwise normal appearance.

Fig. 7. Thirty days after Busulphan treatment. No spermatocytes present. The epithelium consists of Sertoli cells, spermatids and spermatozoa.

Fig. 8. Twenty days after isopropylmethanesulphonate $(100 \mathrm{mg} / \mathrm{kg})$. Appearance comparable to P1. 2, Fig. 7, 30 days after Busulphan.

\section{PLATE 3}

Fig. 9. Rat testis tubule 39 days from Busulphan treatment $(10 \mathrm{mg} / \mathrm{kg})$. Depletion of the seminiferous epithelium by maturation is practically complete and a few spermatozoa remain. The peripheral layer of cells consists of Sertoli cells and a number of new spermatogonia, some of which are dividing.

FIG. 10. Thirty days after injection of isopropylmethanesulphonate $(100 \mathrm{mg} / \mathrm{kg})$. Appearance similar to Pl. 3, Fig. 9.

Fig. 11. Twenty days after isopropylmethanesulphonate $(50 \mathrm{mg} / \mathrm{kg})$. This treatment also causes maturation depletion but the action is less drastic than after the larger dose (compare Pl. 2, Fig. 8). Pre-meiotic spermatocytes are absent but regeneration is in progress as shown by the peripheral spermatogonia.

FIG. 12. Twenty-six days after isopropylmethanesulphonate $(50 \mathrm{mg} / \mathrm{kg})$. Spermatids have now largely disappeared as depletion continues whilst regeneration has continued with the appearance of spermatocytes. 